\title{
Impacto da Covid-19 em crianças
}

\author{
Impact of Covid-19 on children \\ Impacto del Covid-19 en los niños
}

Recebido: 20/07/2021 | Revisado: 28/07/2021 | Aceito: 02/08/2021 | Publicado: 07/08/2021

Rillary Caroline de Melo Silva

ORCID: https://orcid.org/0000-0002-1488-1887

Universidade Federal de Alagoas, Brasil. E-mail: melorillary@gmail.com

Lindynês Amorim de Almeida

ORCID: https://orcid.org/0000-0001-9749-7938

Universidade Federal de Alagoas, Brasil.

E-mail: lindyalmeida7@gmail.com

Hallana Laisa de Lima Dantas

ORCID: https://orcid.org/0000-0001-6721-0860

Universidade Federal de Alagoas, Brasil

E-mail:lanavidas@hotmail.com

Viviane Vanessa Rodrigues da Silva Santana Lima

ORCID: https://orcid.org/0000-0001-6903-1444

Universidade Federal de Alagoas, Brasil.

E-mail: viviane.santana@eenf.ufal.br

Keila Cristina Pereira do Nascimento Oliveira

ORCID: https://orcid.org/0000-0003-0167-5889

Universidade Federal de Alagoas, Brasil

E-mail:keila.oliveira@esenfar.ufal.br

\begin{abstract}
Resumo
O objetivo deste estudo é discutir os impactos da infecção por Covid-19 em crianças a partir de evidências científicas. Trata-se de uma revisão integrativa da literatura, guiada pelas diretrizes PICO e PRISMA, em que foram realizadas buscas nos bancos de dados LILACS, MEDLINE, IBECS, LIS e BDENF durante abril e maio de 2020. A avaliação do nível de evidência foi obtida por meio da classificação de Oxford Centre for Evidence-based Medicine. Em relação ao critério de inclusão não foi delimitado o recorte temporal devido a contemporaneidade do fenômeno estudado e foram inseridos os artigos que na íntegra contemplaram o objetivo do estudo. Assim, foram incluídos oito artigos neste estudo. Estes ressaltaram que recém-nascidos, lactentes e crianças são menos acometidos ou apresentam menos diagnósticos clínicos positivos para o novo coronavírus que os adultos, visto que a maioria apresenta sintomas leves ou difíceis de reconhecer e em alguns casos são assintomáticas, porém o distanciamento social e os comportamentos preventivos do cotidiano continuam sendo importantes para todas as faixas etárias. No cenário da pandemia da Covid-19, é rara a contaminação de crianças, embora sejam suscetíveis ao vírus, em sua maioria apresentam sintomas leves e de curta duração e deve-se considerar aquelas que estão assintomáticas.
\end{abstract}

Palavras-chaves: Criança; Contaminação; Covid-19; Novo coronavírus; SARS-Cov-2.

\begin{abstract}
The aim of this study is to discuss the impacts of Covid-19 infection in children based on scientific evidence. This is an integrative literature review, guided by the PICO and PRISMA guidelines, in which searches were performed in the LILACS, MEDLINE, IBECS, LIS and BDENF databases during April and May 2020. The assessment of the level of evidence was obtained through the Oxford Center for Evidence-based Medicine classification. Regarding the inclusion criteria, the time frame was not defined due to the contemporaneity of the phenomenon studied, and articles that fully contemplated the objective of the study were inserted. Thus, eight articles were included in this study. They highlighted that newborns, infants and children are less affected or have fewer positive clinical diagnoses for the new coronavirus than adults, since most of them have mild or difficult-to-recognise symptoms and in some cases are asymptomatic, but social distancing and everyday preventive behaviors continue to be important for all age groups. In the scenario of the Covid-19 pandemic, contamination of children is rare, although they are susceptible to the virus, most of them present mild and short-lived symptoms and those who are asymptomatic should be considered.
\end{abstract}

Keywords: Child; Contamination; Covid-19; New coronavirus; SARS-Cov-2.

\section{Resumen}

El objetivo de este estudio es discutir los impactos de la infección por Covid-19 en niños con base en evidencia científica. Se trata de una revisión integradora de la literatura, guiada por las guías PICO y PRISMA, en la que se 
realizaron búsquedas en las bases de datos LILACS, MEDLINE, IBECS, LIS y BDENF durante abril y mayo de 2020. La valoración del nivel de evidencia se obtuvo a través del Oxford Clasificación del Centro de Medicina basada en la evidencia. En cuanto a los criterios de inclusión, no se definió el marco temporal debido a la contemporaneidad del fenómeno estudiado, y se insertaron artículos que contemplaban plenamente el objetivo del estudio. Así, se incluyeron ocho artículos en este estudio. Destacaron que los recién nacidos, lactantes y niños se ven menos afectados o tienen menos diagnósticos clínicos positivos para el nuevo coronavirus que los adultos, ya que la mayoría de ellos presentan síntomas leves o difíciles de reconocer y en algunos casos son asintomáticos, pero de distanciamiento social y preventivo cotidiano. Los comportamientos siguen siendo importantes para todos los grupos de edad. En el escenario de la pandemia Covid-19, la contaminación de los niños es rara, aunque son susceptibles al virus, la mayoría presenta síntomas leves y de corta duración y se debe considerar a los que se encuentran asintomáticos.

Palabras clave: Niño; Contaminación; Covid-19; Nuevo coronavirus; SARS-Cov-2.

\section{Introdução}

Sabe-se que a emergente doença do coronavírus teve início em dezembro de 2019, em Wuhan, capital da província de Hubei, localizada na região central da República Popular da China. O novo coronavírus, reconhecido anteriormente por 2019nCoV, foi denominado de SARS-CoV-2. É um vírus de RNA, com fita simples e sentido positivo, altamente contagioso, conhecido por causar doenças respiratórias em humanos e animais e que geralmente pode evoluir a óbito, em casos mais graves. Ocasionou a pandemia, visto que sua principal rota de meio de transmissão é através de aerossóis naturais de humano para humano (BRASIL, 2020).

Assim, convém destacar que os dados epidemiológicos identificados em revisão em 24 de fevereiro de 2020 pelo Centro Chinês de Controle e Prevenção de Doenças foram de 72.314 casos, sendo que menos de $1 \%$ dos casos eram em crianças com menos de 10 anos de idade. Das 1391 crianças avaliadas e testadas, um total de 171 (12,3\%) foi positivo para o SARS-CoV-2. No estudo observou-se que $104(60,8 \%)$ crianças eram do sexo masculino, tinham idade média de 6,7 anos, 131 (76,6\%) possuíam parentes positivos para o vírus e 23 (13,5\%) crianças possuíam familiares com suspeita (Lu, Zhang \& Du, 2020).

Um total de 27 pacientes $(15,8 \%)$ não apresentaram sintomas de infecção ou características radiológicas da pneumonia. Em 08 de março de 2020, houve um óbito. Uma criança de 10 meses com intussuscepção apresentava falência multiorgânica e morreu 4 semanas após a admissão. Com isso, 21 pacientes estavam em condição estável nas enfermarias gerais e 149 receberam alta do hospital (Lu, Zhang \& Du, 2020).

Dessa forma, as crianças também são vulneráveis e o pequeno número de infectadas se deve à baixa exposição ao vírus ou a doenças leves ou por serem assintomáticas, as quais não podem ser identificadas. As crianças, desse modo, são menos propensas a relatar sintomas de Covid-19 (Yonker, Shen \& Kiname, 2020).

Ante o exposto, a revisão tem como objetivo principal discutir os impactos da infecção por Covid-19 em crianças a partir de evidências científicas, apesar desse grupo ser menos propenso a relatar sintomas e se infectar pela Covid-19, assim também pretende-se analisar os motivos para a possível resistência.

\section{Metodologia}

Trata-se de um estudo bibliográfico do tipo revisão integrativa (RI) da literatura, com desenho descritivo e abordagem qualitativa. Este método de pesquisa permite a incorporação das evidências na prática clínica, combinando dados da literatura teórica e empírica, bem como estudos experimentais e não experimentais para se alcançar ampla compreensão do fenômeno analisado (Mendes, Silveira \& Galvão, 2008).

O estudo foi conduzido a partir da orientação de Mendes, Silveira e Galvão (2008) em seis etapas: (1) identificação do tema e definição da questão norteadora; (2) realização de busca e seleção dos estudos baseado em critérios de amostragem; (3) extração de dados; (4) avaliação crítica dos estudos selecionados; (5) interpretação dos resultados; e (6) elaboração da síntese e 
relatório final.

Não obstante, a revisão integrativa de literatura foi adaptada da recomendação denominada PRISMA (Principais Itens para Relatar Revisões sistemáticas e Meta-análises), que consiste em um checklist com 27 itens para manter o rigor metodológico (Galvão, Pansani \& Harrad, 2015).

A pesquisa foi realizada por duas pesquisadoras independentes, utilizando a estratégia PICo, um acrônimo para População (crianças), Interesse (impacto) e Contexto (Covid-19), respectivamente (Santos, Pimenta \& Nobre, 2007). Neste estudo considerou-se a seguinte questão norteadora: quais são os impactos suscetíveis da Covid-19 em crianças?

Constituindo a segunda etapa, os descritores, e suas combinações em português, inglês e espanhol, empregados para pesquisar artigos foram os seguintes: "Criança", "Contaminação", "Covid-19”, "novo coronavírus", "SARS-Cov-2". Utilizouse estratégias de busca avançada com o auxílio do operador booleano "AND" associando os descritores cadastrados nos Descritores em Ciências da Saúde (DeCS) e as respectivas palavras-chave, com o intuito de identificar estudos que contivessem um e outro assunto, além disso a combinação foi realizada nos campos título/title, resumo/abstract e assunto/subject.

Compôs-se a amostra de estudo, após um levantamento de artigos científicos no mês de abril de 2020, em periódicos nas bases de dados: Medical Literature Analysis and Retrieval System Online (MEDLINE), Literatura Latino-Americana e do Caribe em Ciências da Saúde (LILACS), na Base de Dados de Enfermagem (BDENF), Índice Bibliográfico Español en Ciencias de la Salud (IBECS) e no Localizador de Informação em Saúde (LIS). Incluíram-se artigos completos, disponíveis na íntegra, publicados em português, inglês ou espanhol.

Não foi delimitado o recorte temporal como critério de inclusão, com o propósito de abranger o maior número de manuscritos possíveis sobre a temática, levando em consideração a contemporaneidade do fenômeno estudado. Excluíram-se artigos em duplicidade e os que, após inseridos na triagem e lidos na íntegra, não contemplaram o objetivo do estudo.

Os cruzamentos "Contaminação (and) Criança (and) Covid-19", "Covid-19 (and) Criança", "Criança (and) Novo coronavírus", "Criança (and) SARS-Cov-2", identificaram 56 artigos, os quais foram aplicados os critérios de elegibilidade.

Elaborou-se para a extração das evidências (terceira etapa), um instrumento de coleta de dados com o intuito de reunir as seguintes informações dos artigos: identificação, título, autores/ano/periódico, metodologia, objetivos e nível de evidência (Quadro 2). Utilizou-se o item "identificação" para facilitar a discussão sobre cada artigo selecionado na pesquisa e atribuiu-se a identificação A1, A2, A3..., e assim sucessivamente.

Vale ressaltar que os níveis de evidência dos artigos determinam a confiança no uso de seus resultados e fortalecem as conclusões que irão gerar o estado do conhecimento atual do tema investigado, portanto, na pesquisa foram classificados conforme a Classificação de Oxford Centre for Evidence-Based Medicine (Quadro 1). Nesse ínterim, dos dados coletados tabulados e representados no Quadro 2, tem-se destaque os artigos A4 e A7 da categoria 1B, por abordar ensaio clínico controlado. Em seguida, A6 da categoria 3B, por tratar-se de estudo caso-controle. A2 (Hong, Hang, Chung \& Shen, 2020), A5 e A8 compõem a categoria 2C, pois referem-se a estudos ecológicos, enquanto A1 (Schwartz \& Graham, 2020) e A3 a categoria $4 \mathrm{C}$, relatos de casos.

Posteriormente, realizou-se a avaliação crítica dos artigos selecionados (quarta etapa) conforme os critérios: qual é a questão da pesquisa; qual é a base para a questão da pesquisa; por que a questão é importante; como eram as questões de pesquisas já realizadas; a metodologia do estudo está adequada; os sujeitos selecionados para o estudo estão corretos; o que a questão da pesquisa responde; a resposta está correta e quais pesquisas futuras serão necessárias (Mendes, Silveira \& Galvão, 2008).

Nesse contexto, discutiu-se os resultados encontrados fundamentados na análise crítica, propostas de recomendações e sugestões para futuras pesquisas sobre o tema. Na etapa final foi criado um resumo das evidências disponíveis, contemplando a descrição das etapas percorridas e os principais resultados evidenciados da análise dos artigos incluídos, o que resultou na criação de um documento que descrevesse detalhadamente a revisão. É importante salientar que, para a realização da RI, não foi preciso 
encaminhamento do protocolo de pesquisa para a análise por parte do Comitê de Ética e Pesquisa (CEP), conforme as Normas e Diretrizes Regulamentadoras da Pesquisa Envolvendo Seres Humanos - Resolução CNS 466/12. Outrossim, o presente estudo não obteve nenhum tipo de financiamento para a sua realização.

Quadro 1 - Nível de evidência científica de acordo com a Classificação de Oxford Centre for Evidence-Based Medicine.

\begin{tabular}{|c|c|c|c|}
\hline \multicolumn{4}{|c|}{ Nível de evidência científica por tipo de estudo - Oxford Centre for evidence-based-Medicine. } \\
\hline Graus de recomendação & $\begin{array}{l}\text { Nível de } \\
\text { evidência }\end{array}$ & Prevenção/Tratamento - Etiologia & Diagnóstico \\
\hline \multirow{3}{*}{ A } & $1 \mathrm{~A}$ & $\begin{array}{l}\text { Revisão Sistemática (com homogeneidade) de } \\
\text { ensaios clínicos controlados e randomizados. }\end{array}$ & $\begin{array}{c}\text { Revisão sistemática (com } \\
\text { homogeneidade) de estudos } \\
\text { diagnósticos nível } 1 \text { critério de } \\
\text { estudos nível 1B, em diferentes } \\
\text { centros clínicos. }\end{array}$ \\
\hline & 1B & $\begin{array}{l}\text { Ensaio clínicos controlados e randomizados com } \\
\text { intervalo de confiança estreitos. }\end{array}$ & $\begin{array}{l}\text { Coorte validada com bom padrão de } \\
\text { referência critério diagnóstico } \\
\text { testado em um único centro. }\end{array}$ \\
\hline & $1 \mathrm{C}$ & Resultado terapêutico do tipo "tudo ou nada". & $\begin{array}{l}\text { Sensibilidade e especificidade } \\
\text { próximas } \\
\text { de } 100 \% .\end{array}$ \\
\hline \multirow{5}{*}{ B } & $2 \mathrm{~A}$ & $\begin{array}{l}\text { Revisão Sistemática (com homogeneidade) de } \\
\text { estudo de coorte. }\end{array}$ & $\begin{array}{l}\text { Revisão Sistemática (com } \\
\text { homogeneidade) de estudos } \\
\text { diagnósticos de nível > } 2 \text {. }\end{array}$ \\
\hline & 2B & $\begin{array}{l}\text { Estudo de coorte (incluindo ensaio clínico } \\
\text { randomizado de menor qualidade) }\end{array}$ & $\begin{array}{l}\text { Coorte exploratória com bom } \\
\text { padrão de referência critério } \\
\text { diagnóstico derivado ou validada } \\
\text { em amostras ou bancos de dados. }\end{array}$ \\
\hline & $2 \mathrm{C}$ & $\begin{array}{c}\text { Observação de resultados terapêuticos (outcomes } \\
\text { research), estudo ecológico. }\end{array}$ & \\
\hline & $3 \mathrm{~A}$ & $\begin{array}{l}\text { Revisão Sistemática (com homogeneidade) de } \\
\text { estudo caso-controle. }\end{array}$ & $\begin{array}{l}\text { Revisão Sistemática (com } \\
\text { homogeneidade) de estudos } \\
\text { diagnóstico de nível > 3B. }\end{array}$ \\
\hline & 3B & Estudo caso-controle. & $\begin{array}{c}\text { Seleção não consecutivas de casos, } \\
\text { ou padrão de referência aplicado de } \\
\text { forma pouco consistente. }\end{array}$ \\
\hline $\mathrm{C}$ & 4 & $\begin{array}{l}\text { Relato de caso (incluindo estudo de coorte e ou } \\
\text { caso-controle de menor qualidade). }\end{array}$ & $\begin{array}{c}\text { Estudo de caso-controle ou padrão } \\
\text { de referência pobre ou não } \\
\text { independente. }\end{array}$ \\
\hline $\mathrm{D}$ & 5 & \multicolumn{2}{|c|}{$\begin{array}{c}\text { Opinião desprovida de avaliação crítica ou baseada em matérias básicas (estudo } \\
\text { fisiológico ou estudo com animais). }\end{array}$} \\
\hline
\end{tabular}

Fonte: Oxford Centre for evidence-based-Medicine.

\section{Resultados}

Foram encontrados, inicialmente, 56 registros, mediante o cruzamento dos descritores. Após leitura dos títulos, resumos e descritores, foram excluídos 16 artigos, por estarem repetidos, 3 artigos por estarem incompletos e 29 por não atender a questão norteadora, totalizando 48 artigos removidos. A partir disso, foram incluídos nesta pesquisa oito artigos, os quais corresponderam aos critérios de inclusão e exclusão, de acordo com o processo detalhado na Figura 1. 
Figura 1 - Fluxograma de identificação, seleção e inclusão dos artigos investigados baseado na estratégia PRISMA. - Maceió, AL, Brasil, 2020.

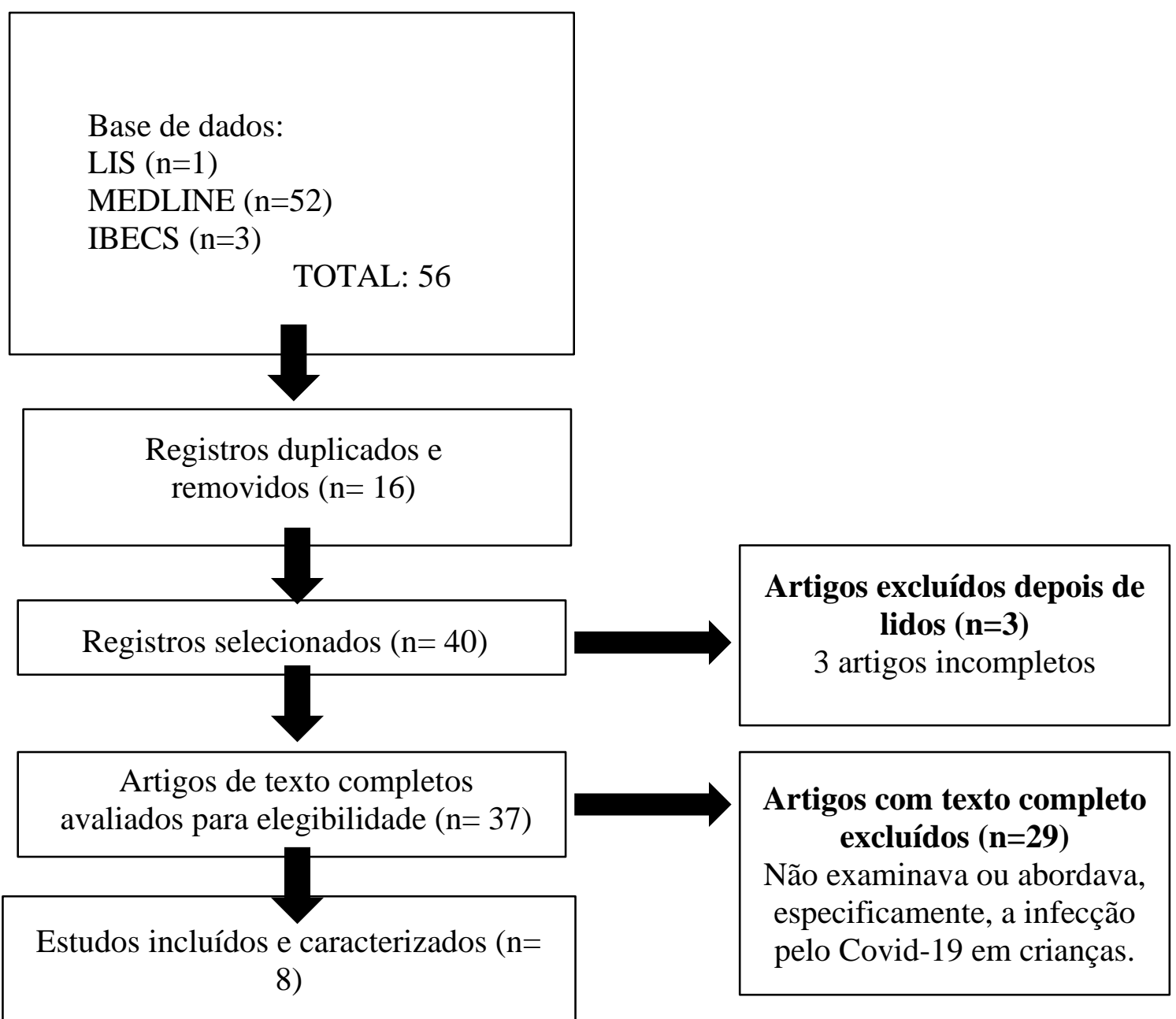

Fonte: Adaptação do Fluxograma PRISMA, 2020.

A principal língua de divulgação desses manuscritos foi o inglês (37 artigos), seguido do espanhol (3 artigos). Além disso, todos os documentos foram publicados a partir de 2020, o que coincide com a incipiente mobilização dos pesquisadores, em escala global, em decorrência da emergente situação em ambientes hospitalares e da saúde em geral. 
Quadro 2 - Artigos incluídos e caracterizados na Revisão Integrativa. Maceió, AL, Brasil, 2020.

\begin{tabular}{|c|c|c|c|c|c|c|}
\hline Id.* & Título & $\begin{array}{l}\text { Autores/Ano/ } \\
\text { Periódico }\end{array}$ & Metodologia & Objetivos & Resultados & $\begin{array}{l}\text { Nível de } \\
\text { evidênci } \\
\text { a }\end{array}$ \\
\hline A1 & $\begin{array}{l}\text { Potential Maternal and } \\
\text { Infant Outcomes from } \\
\text { (Wuhan) Coronavirus } \\
\text { 2019-nCoV Infecting } \\
\text { Pregnant Women: } \\
\text { Lessons from SARS, } \\
\text { MERS, and Other } \\
\text { Human Coronavirus } \\
\text { Infections }\end{array}$ & $\begin{array}{l}\text { SCHWARTZ; } \\
\text { GRAHAM/ } \\
2020 / \\
\text { Viruses }\end{array}$ & Relato de caso & $\begin{array}{l}\text { Analisar os achados } \\
\text { médicos e clínicos de } \\
\text { infecções por } \\
\text { coronavírus } \quad \text { em } \\
\text { mulheres grávidas, a } \\
\text { fim de antecipar } \\
\text { como o recém- } \\
\text { descoberto 2019- } \\
\text { nCoV pode afetar a } \\
\text { morbimortalidade } \\
\text { materna e infantil. }\end{array}$ & $\begin{array}{l}\text { Foi constatado que } \\
\text { nas grávidas com } \\
\text { SARS e MERS, não } \\
\text { houve casos } \\
\text { confirmados re } \\
\text { transmissão intra- } \\
\text { uterina de SARS- } \\
\text { CoV-2 de mães com } \\
\text { COVID-19 para seus } \\
\text { fetos. Todas as } \\
\text { amostras neonatais } \\
\text { testadas, incluindo } \\
\text { placentas em alguns } \\
\text { casos, foram } \\
\text { negativas por RT- } \\
\text { PCR para SARS- } \\
\text { CoV-2. }\end{array}$ & $4 \mathrm{C}$ \\
\hline A2 & $\begin{array}{l}\text { Clinical characteristics } \\
\text { of novel coronavirus } \\
\text { disease } 2019 \text { (Covid-19) } \\
\text { in newborns, infants and } \\
\text { children }\end{array}$ & $\begin{array}{l}\text { Hong, Hao; et. al/ } \\
\text { 2020/ Pediatrics } \\
\text { and Neonatology }\end{array}$ & Estudo ecológico & $\begin{array}{l}\text { Relatar } \\
\text { características } \\
\text { clínicas do Covid-19 } \\
\text { em neonatos, } \\
\text { lactentes e crianças. }\end{array}$ & $\begin{array}{l}\text { A maioria das } \\
\text { crianças infectadas } \\
\text { tem } \\
\text { manifestações } \\
\text { clínicas leves e o } \\
\text { prognóstico é bom. A } \\
\text { maioria } \\
\text { dos pacientes } \\
\text { pediátricos se } \\
\text { recuperaram dentro } \\
\text { de 1 e 2 semanas } \\
\text { após o início. }\end{array}$ & $2 \mathrm{C}$ \\
\hline A3 & $\begin{array}{l}\text { Coronavirus Disease } \\
2019 \text { in Children - } \\
\text { United States, February } \\
\text { 12-April 2, } 2020\end{array}$ & $\begin{array}{l}\text { Covid, C.D.C, et } \\
\text { al./ 2020/ MMWR } \\
\text { Morb Mortal Wkly } \\
\text { Rep }\end{array}$ & Relato de caso & $\begin{array}{l}\text { Relatar os casos de } \\
\text { crianças com Covid- } \\
19 \text { nos Estados } \\
\text { Unidos de } 12 \text { de } \\
\text { fevereiro a } 2 \text { de abril } \\
\text { do ano de } 2020 .\end{array}$ & 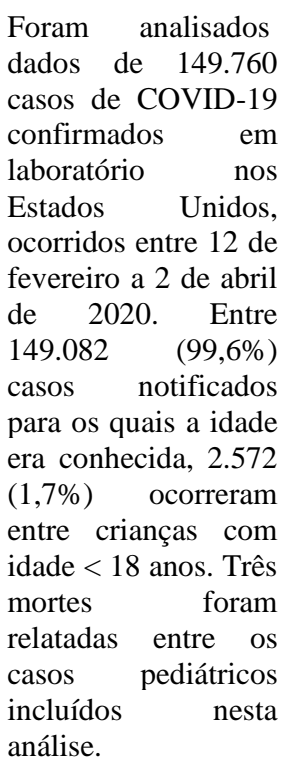 & $4 \mathrm{C}$ \\
\hline
\end{tabular}




\begin{tabular}{|c|c|c|c|c|c|c|}
\hline A4 & $\begin{array}{l}\text { School Opening Delay } \\
\text { Effect on Transmission } \\
\text { Dynamics of } \\
\text { Coronavirus Disease } \\
2019 \text { in Korea: Based on } \\
\text { Mathematical Modeling } \\
\text { and Simulation Study }\end{array}$ & $\begin{array}{l}\text { Kim S; Kim YJ; } \\
\text { Peck KR; Jung } \\
\text { E/2020/ } \\
\text { J Korean Med. Sci. }\end{array}$ & $\begin{array}{lr}\text { Estudo } & \text { de } \\
\text { intervenção do tipo } \\
\text { ensaio } & \text { clínico } \\
\text { controlado } & \end{array}$ & $\begin{array}{l}\text { Quantificar o efeito } \\
\text { do fechamento da } \\
\text { escola na epidemia } \\
\text { Covid-19. }\end{array}$ & $\begin{array}{l}\text { Notou-se que a taxa } \\
\text { de transmissão entre } \\
\text { o grupo de crianças } \\
\text { aumentaria } 10 \text { vezes } \\
\text { após a abertura das } \\
\text { escolas, } \\
\text { aproximadamente } 60 \\
\text { casos adicionais são } \\
\text { esperados de } 2 \text { a } 9 \text { de } \\
\text { março, erame } \\
\text { aproximadamente } \\
100 \text { casos adicionais } \\
\text { de crianças são } \\
\text { esperados de } 9 \text { a } 23 \\
\text { de março. Depois de } \\
23 \text { de março, o } \\
\text { número de casos } \\
\text { esperados para } \\
\text { crianças é } 28,4 \text { por } 7 \\
\text { dias e } 33,6 \text { por } 14 \\
\text { dias. }\end{array}$ & $1 \mathrm{~B}$ \\
\hline A5 & $\begin{array}{l}\text { Epidemiology and } \\
\text { Clinical Characteristics } \\
\text { of Covid-19 }\end{array}$ & $\begin{array}{l}\text { Xiaoyi Huang et } \\
\text { al/2020/Arch Iran } \\
\text { Med March }\end{array}$ & Estudo ecológico & 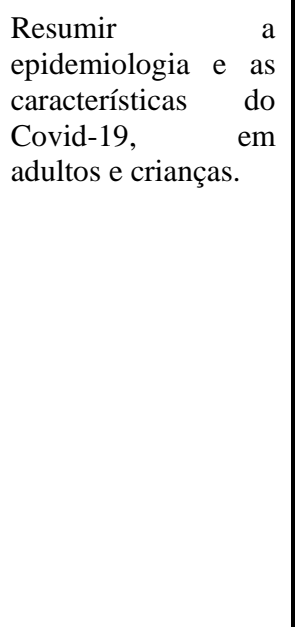 & $\begin{array}{l}\text { A detecção precisa de } \\
\text { RNA foi decisiva } \\
\text { para o diagnóstico de } \\
\text { COVID-19. O } \\
\text { desenvolvimento de } \\
\text { RT-PCR altamente } \\
\text { sensível facilitou } \\
\text { estudos } \\
\text { epidemiológicos que } \\
\text { forneceram } \\
\text { informações sobre a } \\
\text { prevalência, } \\
\text { sazonalidade, } \\
\text { manifestações } \\
\text { clínicas e curso da } \\
\text { infecção por COVID- } \\
\text { 19. }\end{array}$ & $2 \mathrm{C}$ \\
\hline A6 & $\begin{array}{ll}\text { First Pediatric } & \text { Case of } \\
\text { Coronavirus } & \text { Disease } \\
2019 \text { in Korea } & \end{array}$ & $\begin{array}{l}\text { Park, Ji Young; et. } \\
\text { al/ 2020/ Journal } \\
\text { of Korean Medical } \\
\text { Science }\end{array}$ & $\begin{array}{lrr}\text { Relato } & \text { de } & \text { casos } \\
\text { durante } & \text { o } & \text { curso } \\
\text { clínico } & \text { (estudo- } \\
\text { controle) } & \end{array}$ & $\begin{array}{l}\text { Abordar questões } \\
\text { pediátricas } \\
\text { específicas } \\
\text { controle de infecções } \\
\text { e a contribuição das } \\
\text { crianças para a a } \\
\text { disseminação viral } \\
\text { na comunidade. }\end{array}$ & $\begin{array}{l}\text { No primeiro caso } \\
\text { pediátrico r de } \\
\text { COVID-19 na } \\
\text { Coréia, a menina de } \\
10 \text { anos era um } \\
\text { contato próximo de } \\
\text { seu tio e de sua mãe, } \\
\text { que foram } \\
\text { confirmados como } \\
\text { portadores de } \\
\text { COVID-19. A partir } \\
\text { disso, é apresentado o } \\
\text { curso clínico leve de } \\
\text { sua pneumonia que } \\
\text { não exigiu tratamento } \\
\text { antiviral e resultados } \\
\text { de testes virais em } \\
\text { série de várias } \\
\text { amostras. }\end{array}$ & $3 \mathrm{~B}$ \\
\hline A7 & $\begin{array}{l}\text { The different clinical } \\
\text { characteristics of } \\
\text { coronavirus disease } \\
\text { cases between children } \\
\text { and their families in } \\
\text { China - the character of }\end{array}$ & $\begin{array}{l}\text { Su, Liang;et. al/ } \\
2020 / \text { Emerging } \\
\text { Microbes \& } \\
\text { Infections }\end{array}$ & $\begin{array}{lr}\text { Revisão } & \\
\text { retrospectiva dos } \\
\text { achados clínicos, } \\
\text { laboratoriais } & \text { e } \\
\text { radiológicos } & \text { de } \\
\text { nove crianças } & \text { e }\end{array}$ & $\begin{array}{lr}\begin{array}{l}\text { Analisar } \\
\text { diferentes }\end{array} & \text { as } \\
\text { características } & \\
\text { clínicas } & \text { entre } \\
\text { crianças e r suas } \\
\text { famílias infectadas }\end{array}$ & \begin{tabular}{lrr}
$\begin{array}{l}\text { Todas as } \\
\text { tiveram }\end{array}$ & $\begin{array}{r}\text { crianças } \\
\text { resultado }\end{array}$ \\
positivo & \multicolumn{2}{c}{ detectado } \\
após o & início das \\
famílias. & & Três \\
crianças & &
\end{tabular} & $2 \mathrm{~B}$ \\
\hline
\end{tabular}




\begin{tabular}{|c|c|c|c|c|c|c|}
\hline & children with Covid-19 & & suas famílias. & $\begin{array}{l}\text { com coronavírus da } \\
\text { síndrome respiratória } \\
\text { aguda grave } 2 \text {. }\end{array}$ & $\begin{array}{l}\text { apresentavam } \\
\text { sintomas de febre } \\
(22,2 \%) \text { ou tosse } \\
(11,2 \%) \text { e seis } \\
(66,7 \%) \text { crianças não } \\
\text { apresentavam } \\
\text { sintomas. }\end{array}$ & \\
\hline A8 & $\begin{array}{l}\text { Mitigate the effects of } \\
\text { home confinement on } \\
\text { children during the } \\
\text { Covid- } 19 \text { outbreak }\end{array}$ & $\begin{array}{l}\text { Wang, Guanghai; } \\
\text { et. al/ 2020/ The } \\
\text { Lancet }\end{array}$ & Estudo ecológico. & $\begin{array}{l}\text { Atenuar os efeitos do } \\
\text { confinamento em } \\
\text { casa nas crianças } \\
\text { durante o surto de } \\
\text { Covid-19. }\end{array}$ & $\begin{array}{l}\text { As evidências } \\
\text { sugerem que quando } \\
\text { as crianças estão fora } \\
\text { da escola (por } \\
\text { exemplo, fins de } \\
\text { semana e férias de } \\
\text { verão, elas são } \\
\text { fisicamente menos } \\
\text { ativas, têm muito } \\
\text { mais tempo de tela, } \\
\text { padrões de sono } \\
\text { irregulares, e dietas } \\
\text { menos favoráveis, } \\
\text { resultando em ganho } \\
\text { de peso e uma perda } \\
\text { da aptidão } \\
\text { cardiorrespiratória. } \\
\text { Esses efeitos } \\
\text { negativos na saúde } \\
\text { provavelmente são } \\
\text { piores quando as } \\
\text { crianças estão } \\
\text { confinadas em suas } \\
\text { casas sem atividades } \\
\text { ao ar livre e interação } \\
\text { com os amigos. }\end{array}$ & $2 \mathrm{C}$ \\
\hline
\end{tabular}

*Id: Identificação. Fonte: Dados da pesquisa (2020).

Quanto aos achados principais, um dos artigos ressaltou que recém-nascidos, lactentes e crianças são menos contaminadas ou apresentam menos diagnósticos clínicos para o novo coronavírus do que os adultos, pois a maioria apresenta sintomas leves ou difíceis de reconhecer e em alguns casos são assintomáticos (Schwartz \& Graham, 2020). Outro estudo mencionou que quadros sintomáticos podem desencadear febre, tosse seca e fadiga, com alguns sintomas respiratórios superiores, incluindo congestão nasal e coriza; em alguns casos apresentam sintomas gastrointestinais, incluindo desconforto abdominal, náusea, vômito, dor abdominal e diarréia (Hong, Hang, Chung \& Shen, 2020).

\section{Discussões}

No estudo A1 (Schwartz \& Graham, 2020) é salientado a raridade da transmissão vertical de vírus respiratórios, pelo canal vaginal durante o parto ou durante a amamentação, porém em doenças anteriores (Síndrome Respiratória do Oriente Médio - MERS e Síndrome Respiratória Aguda Severa - SARS) oriundas de coronavírus, em alguns casos, necessitou-se de hospitalização, cuidados intensivos e suporte ventilatório para gestantes e posteriores resultados adversos para o feto e o bebê, incluindo restrição de crescimento intra-uterino, parto prematuro, internação na UTI, aborto espontâneo e morte perinatal.

Não obstante, outro estudo (Schwartz, 2020) fez uma análise com 38 mulheres grávidas infectadas por Covid-19 e revelou que, diferentemente de outras coronaviroses, o novo coronavírus não levou a mortes maternas. Entretanto, semelhante às gestações com SARS e MERS, não houve casos confirmados de transmissão intra-uterina de SARS-CoV-2 de mães para seus fetos. Com isso, todas as amostras neonatais testadas, abrangendo, em alguns casos, placentas, foram negativas por RT-PCR 
(sigla em inglês para transcrição reversa seguida de reação em cadeia da polimerase) para SARS-CoV-2. Neste ponto, não há evidências de transmissão de SARS-CoV-2 por via intra-uterina ou transplacentária de gestantes infectadas para seus fetos, porém a análise de casos adicionais é necessária para determinar se isso permanece verdadeiro.

No estudo A2 (Hong, Hang, Chung \& Shen, 2020) evidenciou-se que os casos em crianças, em especial recém-nascidos e bebês foi proveniente do contato com familiares, infectando-os através de aerossóis, visto que a contaminação ocorre por meio da via respiratória, ou, ainda, mediante objetos contaminados (Cao, Chen, Chen \& Chiu, 2020). Contudo, evitar essa relação se torna inviável, pois as crianças que estão na primeira infância (desde o nascimento até os seis anos de idade) precisam de atenção e zelo dos seus cuidadores, visto que um lar saudável exerce intensa importância do psiquismo da criança, como um dos responsáveis diretos pela formação da personalidade do adulto (Macedo \& Amaral, 2009).

Nessa mesma perspectiva, muitos casos confirmados em lactentes e crianças são declarados como doença de cluster, ou seja, infecção de "segunda geração", em que pode ser oriunda do seu grupo familiar. Em contrapartida, não foram encontrados relatos de crianças como a fonte da infecção do adulto (Huang, Wei, Hu, Wen \& Chen, 2020; De Rose et al., 2020).

Em virtude disso, o distanciamento social e os comportamentos preventivos do cotidiano são importantes para todas as faixas etárias, porque os pacientes com doenças menos graves e aqueles sem sintomas, provavelmente desempenham um papel importante na transmissão da doença, fato mais agravante para os grupos de risco, como idosos, cardiopatas, diabéticos, hipertensos, entre outros (Huang, Wei, Hu, Wen \& Chen, 2020).

Segundo o artigo A3 (Covid, 2020), a Covid-19 é mais prevalente dentre a faixa etária dos 18 aos 64 anos e em crianças do sexo masculino menores de um ano de idade, os quais frequentemente apresentavam pelo menos uma condição subjacente, sendo as mais comuns: doença pulmonar crônica (incluindo asma), doença cardiovascular e imunossupressão. Porém, retrata ainda que o número de casos em crianças está aumentando e monitorar a progressão da doença tornou-se um desafio no âmbito da saúde.

É possível destacar a predominância do sexo masculino em todas as faixas etárias pediátricas, incluindo pacientes com idade menor de 1 ano, isso supõe que fatores biológicos podem desempenhar um papel em qualquer diferença na suscetibilidade ao Covid-19 por sexo (Covid, 2020). Paralelamente, as crianças que não têm condições subjacentes, mas possuem o vírus, apresentam sintomas leves e, geralmente, são raros, ou seja, são assintomáticas (Schwartz \& Graham, 2020; Covid, 2020; Kim, Kim, Peck \& Jung, 2020; Wang, Zhang, Zhao, Zhang, \& Jiang, 2020).

A partir desses resultados, constatou-se que crianças e adolescentes são suscetíveis à infecção pelo coronavírus, embora o curso e o desfecho clínico sejam mais favoráveis em crianças menores de 12 anos em comparação com adolescentes e adultos. Uma vez que o sistema imunológico das crianças está se desenvolvendo, provavelmente, ainda não são capazes de iniciar uma tempestade de citocinas (isto é, quando começam a atacar tecidos saudáveis do próprio corpo) semelhante à do adulto (De Rose et al., 2020).

Em razão da alta infectividade do SARS-COV-2 por ser transmitido pelo contato com gotículas respiratórias contaminadas, o estudo A4 (Kim, Kim, Peck \& Jung, 2020) demonstra que o alcance da pandemia seria muito maior se as crianças estivessem nas escolas, devido a interação com professores e com os outros estudantes, sendo possível disseminar o vírus para os pais, avós e pessoas ao redor da criança.

Dessarte, a transmissão através das gotículas do trato respiratório é a principal via de transmissão para Covid-19, mas também pode ser transmitida por contato em superfícies contaminadas e ainda se discute outros mecanismos de transmissão, como a transmissão fecal-oral. Assim, como o ácido nucléico de SARS-CoV-2 foi encontrado por zaragatoas nasofaríngeas e em amostras como escarro, secreções do trato respiratório inferior, sangue e, inclusive, fezes, torna mais propício à expansão da pandemia (Nunes, 2020).

Possivelmente, isso justifica o fato de crianças com condições desfavoráveis de moradia, alimentação e saúde serem 
mais propensas a adquirir a infecção (Calmon, 2020). Nesse sentido, especialmente dada a complexidade envolvida nas causas provocadas durante o processo de incubação do Sars-CoV-2 em humanos (corresponde, em geral, de 1 a 14 dias), o qual pode resultar em óbito, alguns países decretaram a quarentena, medida de saúde pública destinada a conter surtos epidêmicos ou a evitar que um determinado agente infeccioso atinja um território ou grupo social (Santos \& Nascimento, 2014).

Como consequência do isolamento, as evidências sugerem a fragilidade imunológica e perda da aptidão cardiorrespiratória provocadas pela abrupta mudança na rotina dos infantes, já que estão sem atividade ao ar livre e interação com os amigos, visto isso tornam-se fisicamente menos ativos, gastam muito mais tempo usando aparelhos eletrônicos, têm padrões irregulares de sono e dietas menos favoráveis, resultando em ganho de peso conforme o artigo A8 (Park, Han, Park, Kim \& Choi, 2020).

Ademais, evidências têm revelado que há maior risco de crianças e adolescentes sofrerem violência enquanto as escolas estão fechadas devido a emergências de saúde. Para mães, pais e demais cuidadores, o fato de estarem trabalhando remotamente ou mesmo impossibilitados de trabalhar, sem previsão sobre o tempo de duração dessa situação, tende a gerar estresse e medo, inclusive quanto às condições para a subsistência da família, reduzindo a capacidade de tolerância e aumentando o risco de violência contra crianças e adolescentes (Schmidt, Crepaldi, Bolze, Neiva-Silva \& Demenech, 2020).

Vale ressaltar o papel da imunidade inata, a qual é maior no início da vida, porque a resposta imune adaptativa é subdesenvolvida em crianças pequenas, de acordo com o estudo A6 (Park, Han, Park, Kim \& Choi, 2020). Dado que crianças e adultos jovens não têm imunidade específica adaptativa a esse novo vírus, o curso clínico leve em crianças pequenas pode ser explicado por sua resposta imune inata dominante em comparação aos adultos. Isso comprova a baixa incidência de pacientes pediátricos, mas não descarta as prováveis chances de casos graves e até a morte (Park, Han, Park, Kim \& Choi, 2020).

Ressalta-se, sob essa mesma circunstância, que os pacientes pediátricos oferecem oportunidade para os pesquisadores sobre o assunto de obter uma visão crítica da patogênese da doença e orientar futuras vacinas ou desenvolvimento terapêutico (Su et al., 2020). Todavia, o artigo A5 (Huang, Wei, Hu, Wen \& Chen, 2020) se contrapõe ao A6 (Park, Han, Park, Kim \& Choi, 2020) quando refuta que a função imunológica das crianças encontra-se imatura, deixando estas suscetíveis a infecções do sistema respiratório e seus sintomas são mais diversificados, logo, é mais fácil a diminuição da formação de anticorpos.

Com base em A7 (Su, et al., 2020), as crianças apresentam sintomas leves ou são assintomáticas através de quatro suposições: (1) As crianças são infectadas por suas famílias e como o SARS-CoV-2 é um vírus de RNA, é possível que ocorra erros na replicação, mutação e sobrevivência sem reconhecimento pelo sistema imunológico, mas também pode causar um declínio na virulência, desse modo são infectadas com vírus de segunda, terceira ou até quarta geração, com isso apresentam sintomas mais leves; (2) devido a diferenças nas respostas imunes de crianças em comparação com adultos.

Na mesma linha de raciocínio, outro direcionamento (3) é o de que o número ou a função dos receptores de angiotensina 2 (ACE2) - na qual sua eficiência é considerada um determinante essencial da SARS-CoV-2 em crianças não é tão bom quanto em adultos (Su, et al., 2020). Recentemente, um estudo investigou o papel do receptor ACE2 e descobriu que o SARS-CoV-2 usa o receptor SARS-coronavírus ACE2 e a serina protease celular (TMPRSS2) para entrada nas células-alvo (Hoffmann, KleineWeber, Krüger, Müller, Drosten \& Pöhlmann, 2020). Portanto, uma expressão limitada da ACE2 na infância, em um período que os pulmões ainda estão em desenvolvimento, poderia proteger as crianças das formas graves de doença (Safadi, 2020).

Além disso, a alta expressão de ACE2 pode prolongar o ciclo de vida do vírus, melhorar a replicação e mediar a penetração no hospedeiro. Isso fortalece a ideia de que a susceptibilidade e severidade do vírus possam estar relacionadas aos níveis quantitativos e qualitativos do receptor ACE2 no organismo (Andrade et al., 2020). Sabe-se que a distribuição dos receptores ACE2 em diferentes órgãos e populações é diferente. Logo, supõe-se que diferentes níveis ou funções de receptores em crianças e adultos determinam a gravidade da doença. (4) Outra razão: como as crianças têm menos doenças básicas e fumam menos, portanto, tem vias respiratórias mais saudáveis, elas têm fortes capacidades de autocura ( $\mathrm{Su}$, et al., 2020; Hoffmann, 
Kleine-Weber, Krüger, Müller, Drosten \& Pöhlmann, 2020).

Estudos comprovam que a resposta imune inata, ou seja, a resposta precoce, a qual é a primeira linha de defesa do organismo, quando direcionada amplamente a grupos de patógenos, tende a ser mais ativa em crianças, uma vez que as células desse sistema respondem imediatamente a invasores estrangeiros. O sistema imunológico adaptativo, por outro lado, aprende a reconhecer patógenos específicos, mas leva mais tempo para se juntar à batalha (Park, Han, Park, Kim \& Choi, 2020; Su, et al., 2020; Hoffmann, Kleine-Weber, Krüger, Müller, Drosten \& Pöhlmann, 2020). A ACE2 está relacionada com a imunidade adaptativa, e sua expressão aumentada pode estar relacionada com o aumento dos níveis de citocinas em pacientes críticos com COVID-19, causando um aumento acentuado na liberação de citocinas, que supostamente não acontece nas crianças, como foi citado anteriormente (Andrade et al., 2020).

Se a resposta imune inata for mais forte em crianças expostas à SARS-CoV-2, elas podem combater a infecção mais rapidamente do que os adultos, sofrendo apenas sintomas leves, isso corrobora com o que foi encontrado na pesquisa A6 (Park, Han, Park, Kim \& Choi, 2020), discutida anteriormente. Outras coronaviroses, incluindo SARS e MERS, apresentam o mesmo padrão.

\section{Limitações do estudo}

Considerando a fase inicial da pandemia, este estudo apresentou como limitação o curto intervalo de tempo analisado, bem como o número reduzido de publicações que investigaram os agravos à saúde da criança pela Covid-19, em relação às alterações fisiológicas características dos sistemas orgânicos do infante. Assim, pontua-se a importância da realização de novos estudos sobre a temática, especialmente no Brasil.

\section{Considerações Finais}

Esta pesquisa revelou a complexidade da relação entre imunidade infantil e o do adoecimento por Covid-19, embora haja investigações concluídas e em curso, a taxa de infectividade em crianças está sujeita às atualizações, bem como ao comportamento assintomático da doença, que por sua vez contribui para uma baixa notificação destes casos, convertendo-se em um desafio para comunidade científica. A partir dos resultados nota-se uma menor taxa de infecção e de gravidade da doença em crianças quando comparadas a adultos, fato evidenciado pelo menor número de crianças hospitalizadas e pela menor taxa de casos críticos e graves.

Decerto que o comportamento da infecção seja exponencial e que pessoas de todas as idades possam progredir para um estágio crítico, os casos infantis são caracterizados como raros. Tendo em vista que a maioria das crianças apresentaram sintomas leves ou difíceis de identificar, logo, a quantidade de casos pediátricos assintomáticos por SARS-CoV-2 é maior. Assim, percebeu-se a grande necessidade e urgência de se promover o aprofundamento nos assuntos sobre tais questões, visto que as crianças raramente experimentam as formas graves da doença.

\section{Referências}

Andrade, P. M., Barbosa, S. C. S., Malta, V. F. M., Silva, P. H. A., Malta, R. W. P., Galindo, V. A., \& Dantas, V. G. L. (2020). A influência da variação da expressão de ACE2 na severidade da COVID-19 em adultos e crianças: uma revisão sistemática. Braz. Ap. Sci. Rev, Curitiba, 4(6), 3792-3804. https://www.brazilianjournals.com/index.php/BASR/article/view/21442/17109

Brasil. Governo do estado do Ceará. (2020). Plano estadual de contingência para resposta às emergências em saúde pública: novo Coronavírus (2019-nCoV). Secretaria da Saúde. https://www.saude.gov.br/images/pdf/2020/fevereiro/13/PLANO-DE-CONTINGENCIA-novo-coronavirus-CEAR---EM-REVIS--O.pdf

Calmon, T. V. L. (2020). As condições objetivas para o enfrentamento ao Covid-19: abismo social brasileiro, o racismo, e as perspectivas de desenvolvimento social como determinantes. NAU Social, 11(20), 131-136. https://periodicos.ufba.br/index.php/nausocial/article/view/36543

Cao, Q., Chen, Y. C., Chen, C. L., \& Chiu, C. H. (2020). SARS-CoV-2 infection in children: Transmission dynamics and clinical characteristics. Journal of the 
Formosan Medical Association, 119(3), 670. https://pubmed.ncbi.nlm.nih.gov/32139299/

Covid, C.D.C, et al. (2020). Coronavirus disease 2019 in children-United States, february 12-april 2, 2020. Morbidity and Mortality Weekly Report, 69(14), 422. https://www.ncbi.nlm.nih.gov/pubmed/32271728

De Rose, D. U., Piersigilli, F., Ronchetti, M. P., Santisi, A., Bersani, I., Dotta, A., ... \& Auriti, C. (2020). Novel coronavirus disease (Covid-19) in newborns and infants: what we know so far. Italian journal of pediatrics, 46(1), 1-8. https://ijponline.biomedcentral.com/articles/10.1186/s13052-020-0820-X

Galvão, T. F., Pansani, T. D. S. A., \& Harrad, D. (2015). Principais itens para relatar Revisões sistemáticas e Meta-análises: A recomendação PRISMA. Epidemiologia e Serviços de Saúde, 24, 335-342. http://www.scielo.br/scielo.php?script=sci_arttext\&pid=S2237-96222015000200335.

Hoffmann, M., Kleine-Weber, H., Krüger, N., Müller, M., Drosten, C., \& Pöhlmann, S. (2020). The novel coronavirus 2019 (2019-nCoV) uses the SARScoronavirus receptor ACE2 and the cellular protease TMPRSS2 for entry into target cells. BioRxiv. https://www.biorxiv.org/content/10.1101/2020.01.31.929042v1.abstract

Hong, H., Wang, Y., Chung, H. T., \& Chen, C. J. (2020). Clinical characteristics of novel coronavirus disease 2019 (Covid-19) in newborns, infants and children. Pediatrics and neonatology, 61(2), 131. https://www.pediatr-neonatol.com/article/S1875-9572(20)30026-7/pdf

Huang, X., Wei, F., Hu, L., Wen, L., \& Chen, K. (2020). Epidemiologia e características clínicas do Covid-19. Arquivos da medicina iraniana , 23 (4), 268-271. http://www.aimjournal.ir/Article/aim-15538

Kim, S., Kim, Y. J., Peck, K. R., \& Jung, E. (2020). School opening delay effect on transmission dynamics of coronavirus disease 2019 in Korea: based on mathematical modeling and simulation study. Journal of Korean medical science, 35(13). https://synapse.koreamed.org/articles/1145994?viewtype=pubreader

LU, X., ZHANG, L., \& DU, H. (2020). Original: SARS-CoV-2 Infection in Children. The New England Journal of Medicine, 382 (17). https://www.nejm.org/doi/10.1056/NEJMc2005073

Macedo, R. C., \& do Amaral Costa, N. R. (2009). Um lar saudável para uma criança saudável. Investigação, 9(1). http://publicacoes.unifran.br/index.php/investigacao/article/view/37

Mendes, K. D. S., Silveira, R. C. D. C. P., \& Galvão, C. M. (2008). Revisão integrativa: método de pesquisa para a incorporação de evidências na saúde e na enfermagem. Texto \& contexto-enfermagem, 17, 758-764. http://www.scielo.br/scielo.php?script=sci_arttext\&pid=S0104-07072008000400018

Nunes, V. M. D. A. (2020). Covid-19 e o cuidado de idosos: recomendações para instituições de longa permanência. EDUFRN - Editora da UFRN. https://repositorio.ufrn.br/jspui/handle/123456789/28754

Park, J. Y., Han, M. S., Park, K. U., Kim, J. Y., \& Choi, E. H. (2020). First pediatric case of coronavirus disease 2019 in Korea. Journal of Korean medical science, 35(11). https://synapse.koreamed.org/DOIx.php?id=10.3346/jkms.2020.35.e124

Safadi, M. A. P. (2020). The intriguing features of Covid-19 in children and its impact on the pandemic. $J$ Pediatr, 96(3), 265-268. https://www.scielo.br/j/jped/a/R68f5rLHYzT7TcKHFYVFZGq/?lang=pt\&format=pdf

Santos, C. M. D. C., Pimenta, C. A. D. M., \& Nobre, M. R. C. (2007). A estratégia PICO para a construção da pergunta de pesquisa e busca de evidências. Revista Latino-Americana de Enfermagem, 15, 508-511. https://doi.org/10.1590/S0104-11692007000300023.

Santos, I. A. D., \& Nascimento, W. F. D. (2014). As medidas de quarentena humana na saúde pública: aspectos bioéticos. Revista Bioethikos, Centro Universitário São Camilo, 8(2), 174-185.https://saocamilo-sp.br/assets/artigo/bioethikos/155563/A05.pdf

Schmidt, B., Crepaldi, M. A., Bolze, S. D. A., Neiva-Silva, L., \& Demenech, L. M. (2020). Saúde mental e intervenções psicológicas diante da pandemia do novo coronavírus (Covid-19). Estudos de Psicologia (Campinas), 37. http://www.scielo.br/scielo.php?script=sci_arttext\&pid=S0103$166 X 2020000100501 \& \operatorname{lng}=$ en $\&$ nrm=iso

Schwartz, D. A. (2020). An analysis of 38 pregnant women with Covid-19, their newborn infants, and maternal-fetal transmission of SARS-CoV-2: maternal coronavirus infections and pregnancy outcomes. Archives of pathology \& laboratory medicine, 144(7), 799-805. https://www.archivesofpathology.org/doi/10.5858/arpa.2020-0901-SA?url_ver=Z39.88-2003\&rfr_id=ori:rid:crossref.org\&rfr_dat=cr_pub\%3dpubmed

Schwartz, D. A., \& Graham, A. L. (2020). Potential maternal and infant outcomes from coronavirus 2019-nCoV (SARS-CoV-2) infecting pregnant women: lessons from SARS, MERS, and other human coronavirus infections. Viruses, 12(2), 194. https://www.mdpi.com/1999-4915/12/2/194

Su, L., Ma, X., Yu, H., Zhang, Z., Bian, P., Han, Y., ... \& Gai, Z. (2020). The different clinical characteristics of corona virus disease cases between children and their families in China-the character of children with Covid-19. Emerging microbes \& infections, 9(1), 707-713. https://www.tandfonline.com/doi/full/10.1080/22221751.2020.1744483

Wang, G., Zhang, Y., Zhao, J., Zhang, J., \& Jiang, F. (2020). Mitigate the effects of home confinement on children during the Covid-19 outbreak. The Lancet, 395(10228), 945-947. https://www.thelancet.com/pdfs/journals/lancet/PIIS0140-6736(20)30547-X.pdf

Yonker, L. M., Shen, K., \& Kinane, T. B. (2020). Lessons unfolding from pediatric cases of Covid-19 disease caused by SARS-CoV-2 infection. Pediatric pulmonology, 55(5), 1085. https://onlinelibrary.wiley.com/doi/full/10.1002/ppul.24748 